\title{
TEMATIZANDO O ENSINO RELIGIOSO - IDENTIDADE E DES-IDENTIFICAÇÕES
}

\section{To tematizar the religious education - identity and des-identifications}

Celma Christina Cruz da Rocha ${ }^{1}$

\section{Resumo}

O artigo tem como principal questão de reflexão a constituição da identidade religiosa. Utilizou-se como ferramenta teórica de diálogo elementos das contribuições de pensadores contemporâneos, num recorte específico que se refere à questão da identidade, das práticas discursivas e à constituição da identidade religiosa. O texto pretende ser uma contribuição instigante, no sentido de uma provocação permanente às relações de poder-saber-subjetividade. Contêm manifestos o desejo e o esforço para abrir novos caminhos éticos numa perspectiva da constituição de uma subjetividade que se exerce a partir da vigilância e de um ativismo incessante que não busca o fim da luta, mas a liberdade de participação nela.

Palavras-chave: Identidade; Identidade Religiosa; Práticas Discursivas.

\section{Abstract}

The purpose of this article is to examine the construction of the religious identity using as a theoretical tool for the dialog elements provided by contemporary thinkers, stressing specifically the issue of identity, discoursive practices and the constitution of religious identity. The author's intention is to offer an instigating contribution in the sense of a permanent challenge to the relations between power, knowledge and subjectivity. Here the author manifests the desire and effort to open up new ethical dimensions in the constitution of a subjectivity that is exercise on the basis of vigilance and an unceasing activism that does not search for the end of the struggle, but the freedom to participate in it.

Keywords: Identity; Religious identity; Discursive practise.

1 Doutora em Teologia pela EST/ São Leopoldo.

E-mail: cchristinarocha@ig.com.br 
(...) Mas se interpretaré apoderar-se de um sistema de regras que não tem em si a significação essencial e impor-lhe uma direção, dobrá-lo a uma nova vontade, fazê-lo entrar em outro jogo e submetê-lo a novas regras, então o devir da humanidade é uma série de interpretações (FOUCAULT, 2000, p. 270).

Vivemos um tempo em que nós, educadores e educadoras, nos vemos levados a, mais do que nunca, fazer perguntas vitais sobre nosso ofício e nosso papel, sobre nosso trabalho e nossa responsabilidade. Um projeto educativo pode ser sempre outra coisa, pode adquirir outros significados, pode incorporar outros sentidos. É possível fazer outras perguntas, definir outros problemas de outra forma. Assim, nós educadores e educadoras abrimos 0 campo do social e do político para a produtividade e a polissemia, para a multiplicidade e a produção de novas possibilidades.

No presente artigo faço considerações sobre elementos tematizados na reflexão contemporânea, num recorte específico que se refere à questão da identidade e das práticas discursivas e à constituição da identidade religiosa. Michel Foucault, Stuart Hall, Kenneth J. Gergen e Madan Sarup são os principais interlocutores que tenho como referência para enriquecer a discussão no sentido de abrir tramas de uma tessitura que, creio, precisa ser continuamente constituída.

Ao escrever o presente artigo é preciso assumir minha provisoriedade, parcialidade e, a partir dos próprios paradigmas de referência que utilizo para esta análise, é preciso afirmar que o que aqui se apresenta é apenas um olhar entre outros tantos possíveis.

Uma concepção corrente sobre a experiência religiosa é de que esta se situa como fundamento último, caracterizando-se como zona de sentido da pessoa.

No fundo de toda a situação verdadeiramente religiosa encontra-se a referência aos fundamentos últimos do homem: quanto à origem, quanto ao fim e quanto à profundidade. 0 problema religioso toca o homem em sua raiz ontológica.(...) Pode caracterizar-se o religioso como zona de sentido da pessoa (ZILLES, 1991, p. 6).

Assumo a suposição que a experiência religiosa está vinculada a formas referenciais de significação e articulação da existência; que essas formas (fôrmas de significação) referenciais são constituídas pelo(s) discurso(s) do/ religioso(s); que esse(s) discurso(s) se constitui(em) num determinado espaço/tempo, perpassado pelo imbricamento de culturas, políticas, determinantes econômico-sociais, éticas e estéticas; que esse(s) discurso(s) valida(m) formas de existencialidade (exercício do existir); que o(s) discurso(s) religioso(s) 
constitui(em)-se referências de significação da vida(s), da morte(s), do mundo(s), das relações, da(s) moral(is) e da(s) ética(s) etc., e, ainda, que são constituidores de identidade(s).

Segundo Spink (1999) as práticas discursivas são estratégias lingüísticas delineadas para conversar, explicar, organizar e dar sentido ao mundo, cujas especificidades estão vinculadas ao contexto que as produzem.

Sendo assim, e partindo das considerações feitas acima, existe uma gama de implicações que precisam ser analisadas. Procuro tematizá-las, neste artigo, abordando questões relativas à constituição da identidade do ser contemporâneo e ao discurso sobre o religioso.

\section{Novas demandas identitárias}

A velocidade das mudanças sociais, políticas, econômicas, tecnológicas, culturais e outras, ocorridas nas últimas décadas, tem afetado a vida de homens e mulheres contemporâneos. O diagnóstico da fragmentação da subjetividade contemporânea relaciona-se ao impacto das mais diversas solicitações que convidam a um processo constante de reinvenção de si, de modo a atender a demandas emergentes e situações instáveis.

A compreensão sobre a identidade tem-se modificado consideravelmente ao longo deste século, e, com essa modificação, modificam-se também as características das interações sociais.

A interconexão possível entre as diferentes áreas do planeta gera ondas de transformação social, causando um constante exame das práticas sociais à luz das informações recebidas sobre aquelas próprias práticas, alterando constitutivamente seu caráter, Hall (1999, p. 15). Tal processo se dá como reflexo das mudanças constantes, rápidas e impactantes que as sociedades complexas estão vivenciado.

Para Crespi (1999, p. 12-13), o aumento do grau de complexidade das sociedades desenvolvidas e a intensificação do processo dos trânsitos de informação globais incidiram profundamente sobre as percepções que os indivíduos têm de si mesmos e de suas relações com a sociedade. Tanto as identidades individuais quanto as identidades no sentido de pertença coletiva tornaram-se problemáticas por causa da crescente diferenciação dos papéis e dos âmbitos de pertença, provocando, por reação, a procura de identificações mais imediatas.

A emergência de demandas identitárias na cena contemporânea representa uma dificuldade de vivenciar os efeitos dos deslocamentos que incidem nos contextos locais; uma recusa dos grandes modelos e de suas tendências globalizantes e uma defesa da "autenticidade" das experiências particula- 
res e enraizadas num determinado tempo e espaço comunitário contra as forças desterritorializantes, "abstratas", do mercado ou da cultura de massas. Recentemente, Touraine (1994) tem feito da disjunção entre mercado e cultura o cerne de sua análise sobre os impasses da modernidade tardia e a base de sua defesa da introdução de um princípio não-social de resistência ao capital e à comunidade, que ele chama de "sujeito".

As identidades reagem, buscando uma forma de neutralizar o sentimento de ansiedade ou pânico ante a incerteza, a instabilidade e a permanente redefinição das regras e cenários que se instalam. Enceta-se uma luta para restaurar um mundo nostalgicamente idealizado de simplicidade de vida, durabilidade dos arranjos sociais e proximidade e confiabilidade das relações entre as pessoas. Em nome da identidade busca-se encontrar na origem comum ou num destino manifesto a orientação que contradiga as tendências desestabilizadoras e a incerteza do presente.

Castells (1997, p. 66) faz uma breve descrição do processo citado quando comenta que o caráter defensivo de muitas práticas identitárias se dirige contra os efeitos da globalização, os processos de formação de redes e de flexibilização e a crise da família patriarcal:

Quando o mundo se torna grande demais para ser controlado, os atores sociais buscam encolhê-lo de volta ao tamanho e alcance deles. Quando as redes dissolvem o tempo e o espaço, as pessoas se ancoram em lugares, e recuperam sua memónia histórica. Quando a reprodução patriarcal da personalidade fracassa, as pessoas afirmam o valor transcendente da família e da comunidade, como vontade de Deus.

A identidade não é algo inato. A concepção que o indivíduo tem de si próprio como uma identidade unificada é o resultado de uma elaboração discursiva que o constrói como tal. Concebe-se que o conceito de identidade unificada é uma "narrativa do eu", construída por cada um de nós, e que 0 homem contemporâneo vive em permanente confronto com uma multiplicidade enorme de identidades possíveis e cambiantes com as quais ele temporariamente pode se identificar (LACLAU, 1990, p. 40).

Na célebre afirmação de Wittgenstein apud Chauviré (1989, p. 63) "Os limites da linguagem significam os limites de meu mundo". Os termos de que dispomos para tornar acessíveis nossa personalidade (os vínculos e as emoções, motivações, pensamentos, valores, opiniões, etc.) impõem limites a nossas atuações, afirma Gergen (1992, p. 24). A vida cultural do século XX está dominada por grandes vocabulários vinculados ao eu, como herança do século XIX, que atribuía a cada indivíduo traços de personalidade relevantes para o estabelecimento de relações comprometidas, amizades fiéis e objetivos vitais. 
A partir do século XX, essa cosmovisão é contestada. Há uma fragmentação das concepções, em conseqüência da multiplicidade das formas de relações, que também se manifestam incoerentes e desconectadas. A saturação social conforme Gergen (1992, p. 26) está vinculada às mudanças de concepção sobre "o que somos", onde certas pautas da vida cultural perdem credibilidade enquanto outras se tornam cada vez mais valorizadas. Ao transformar a concepção "do que somos" transformam-se também os modos de convivência possibilitando uma multiplicidade de linguagens. Cada coisa que antes se sabia com certeza passa a ser questionada e se revela motivo de dúvida. A "erosão" do eu identificável acontece a partir de uma gama de concepções e práticas características dessa contemporaneidade (GERGEN, 1992).

As pessoas existem num mundo de construção e reconstrução permanente. Cada realidade do eu pode ser questionado de forma reflexiva, sendo ensaio para alguma outra realidade, como se fosse um jogo.

O ser pós moderno é um nômade inquieto. Cada modalidade do ser se converte em uma pequena prisão que nos instiga a buscar liberdade de expressão, e cada libertação, não faz se não criar um novo marco de contenção (GERGEN, 1992, p. 222).

O eu é concebido como múltiplo, multifacetado, fragmentado. Questiona-se o conceito de um eu básico, verdadeiro e autêntico e a conseqüente necessidade de coerência e congruência pessoal. Identificar, fixando, é aprisionar a liberdade de que este eu se diga de forma diversa, em seu processo de criar-se sempre como novo. Sem que seja possível fixar uma identidade, não é mais possível que se diga "a coisa em si". O "em si" é inapreensível, não existe como tal, pois é sempre diverso.

Tendo em conta essas considerações, Hall formula a idéia de Tradução e a relaciona com a questão da identidade. A palavra Tradução tem etimologia latina e significa transferir, transportar entre fronteiras. Assim, através deste conceito é possível pensar as identidades como migrações entre identidades, entre culturas, como necessidade de tradução e de negociação entre instâncias, afirma Hall (1999, p. 274-316).

Há uma estabilidade dos sistemas simbólicos. A capacidade do ser humano de produzir sentido e de identificar-se como membro de uma comunidade acontece numa perspectiva híbrida de difícil fixação. A situação contemporânea exige um esforço para compreender o que está acontecendo para além dos preconceitos, para além dos limites que nos são impostos pela cultura particular no seio da qual se estrutura determinada forma de fazer sentido.

Há um abandono da busca da garantia da consistência no absoluto ou em qualquer princípio transcendente da subjetividade. 
A subjetividade deixa de recorrer, para organizar-se, a imagens a priori e 0 modo de subjetivação correlato e inseparável implica, pois, estabelecer bases para uma subjetividade (...) distante do equilíbrio, meta-estável, fazendo-se e refazendo-se a partir de rupturas de sentido, incorporando composições de forças, circunscrevendo-se para além da consciência, forjando-se no âmbito do caos (...) em constante devir (LÉVY, 2000, p. 57).

\section{Des-identificações - sendo estrangeiro...}

Madan Sarup, no texto "Hogar, Identidad y Educacion", problematiza uma das características da contemporaneidade, que é o sentimento de desterritorialização, de estar sem pátria, sem uma única definição, estar em processo de desidentificação e constituição de novas identificações. A hipótese com que trabalho considera este sentimento plenamente vivido também no que diz respeito à identidade religiosa ou à sua perda. Muitas pessoas que transitam hoje pelo espaço do ecumenismo, vinculadas à educação religiosa no espaço secular, são, nesta perspectiva, estrangeiras.

No texto citado, Sarup (1995, p. 269) aborda-se a identidade do "ser contemporâneo" como híbrida e múltipla, constituindo-se através da comunidade, cruzando fronteiras e limites. Para o autor, este evidente interesse pela identidade é fascinante e ele opta por tematizá-la numa perspectiva do imigrante. Considerando, a partir de minha leitura pessoal, existir uma poética no texto, que o faz metáfora de questões de subjetividade existencial, permito-me destacar as idéias que ele tematiza, consoante uma perspectiva não apenas relacionada ao estrangeiro enquanto aquele que está distante de seu lugar de origem, mas como um estado de possibilidade - o estar sendo - que é gestado em nossa interioridade nos distintos momentos de nossa trajetória de identificação ou "des-identificação" com lugares, lares, relacionamentos, culturas, formas de expressão religiosa, etc.

Sarup define o imigrante como uma pessoa que está cruzando fronteiras. Ela busca um lugar que lhe possibilite um novo começo, e ao mesmo tempo em que precisa suportar a dor da separação precisa enfrentar um novo espaço que lhe é diferente e hostil. O autor trabalha com a idéia de casa como um lugar de pertença e de estabilidade da pessoa. Pergunta: o que faz com que um lugar se constitua em lar? Onde está o lar? Ele faz uma pergunta fenomenológica: "Tu te encontras no mundo como se estivesses em tua casa?" O autor afirma que "Em certos lugares e momentos, me encontro como se estivesse em minha casa; me sinto seguro e bem com os demais. No entanto, em outros, me dá a sensação de que não sei de onde sou" (SARUP, 1995, p. 269). 
Sarup (1995) fala de casa e de lugar não numa perspectiva de fixação a espaços que em determinados agoras foram existencialmente referenciais para a pessoa, mas provoca a percepção do existir em constante translado. Traz a idéia de movimento onde o "lar está onde está o coração". " Estar no lar" é estar em experiências e atividades valiosas, vivendo ou recordando acontecimentos pessoais significativos.

Quando um imigrante cruza uma fronteira, encontra manifestações de hostilidade e de boas-vindas. Aceita-se e rejeita-se o imigrante de muitas maneiras. O fortalecimento de vínculos culturais é uma forma de enfrentamento das hostilidades. Por exemplo, "para os membros de grupos étnicos minoritários, sua religião, que constitui um dos aspectos de sua cultura, é um apoio valioso em meio a um ambiente hostil" (SARUP, 1995, p. 271).

Muitas pessoas não se sentem em casa onde estão e voltam atrás, em busca de suas raízes. A busca de "suas raízes" é a busca por uma revalorização de sua identidade. Citando Melanie Klein, Sarup (1995, p. 272) argumenta que quase sempre se supõe que seja bom ter raízes profundas. Torna-se, no entanto, necessário que se problematize a própria idéia da possibilidade de "fixar raízes". Há uma ambivalência na palavra lugar. Os lugares se constroem socialmente e essa construção tem a ver com o poder. O lugar se relaciona com a tradição e essa também se cria e recria continuamente. A tradição é fluida e sempre está se reconstruindo. A tradição se refere à mudança, mudança que não se reconhece.

As relações se referenciam sempre a partir de um lugar. Essa forma de vinculação primordial e "localizável" tem uma importância humana fundamental. Mas, para o imigrante, há uma distância entre essas referências primordiais e o seu momento presente. Uma manifestação explícita desta situação se dá pela linguagem. $O$ imigrante enfrenta a separação entre 0 significado e o significante. As palavras não se referem às coisas do mesmo modo inquestionável, como se referiam na língua materna. $O$ estrangeiro precisa inventar um lugar e uma identidade para si mesmo sem os apoios tradicionais. Torna-se um estrangeiro residente, uma criatura híbrida, que precisa renascer, refazer-se como uma colcha de retalhos.

Sarup (1995, p. 271) pergunta: como os marcos culturais de referência mantêm em seu lugar as personalidades individuais? Como se imaginam e representam os lugares? Como influem nas identidades pessoais? Como se unem os mundos da imaginação e da representação? O trajeto transforma a identidade; nele, nossa subjetividade se reconstrói. Nessa transformação, cada passo adiante pode ser um passo atrás. $\mathrm{O}$ imigrante está aqui e ali. $\mathrm{O}$ exílio pode ser mortal, mas pode também ser muito criativo. $O$ exílio pode ser uma aflição, mas também uma transformação: pode constituir um recurso. A identidade não tem a ver com o ser, mas sim com o chegar a ser (SARUP, 1995, p. 173). 
Os imigrantes chegam às fronteiras e são convidados ao exterior. As fronteiras são lugares de comunicação e intercâmbio. Viajantes que vivem nas fronteiras vivem os limites entre estados: "sentimentos e pensamentos, o privado e o público", "o polaco e o inglês", "o cristão e o budista". "A fronteira sempre é ambivalente: umas vezes se considera parte intrínseca do interior: outras se considera parte do deserto caótico exterior" (SARUP, 1995, p. 274).

Citando o trabalho de Julia Kristeva, Sarup traz a idéia do estrangeiro como o desconhecido no eu, no sentido profundo de ser de uma pessoa, a diferença da aparência externa e da própria idéia consciente de si. $\mathrm{O}$ autor pontua que o pensamento sobre o estrangeiro varia de época para época e a mudança de categoria social dos estrangeiros, imperativa na nossa atualidade, nos leva à necessidade de refletir sobre a nossa capacidade de aceitar novas modalidades de diferença.

Afinal, quem é estrangeiro? Há um exercício de poder sobre a constituição desta identidade bem como da possibilidade de constituir-se uma outra. Há pessoas que não querem e não podem integrar-se aqui, nem regressar a seu lugar de origem. Em que lugar habitam? Onde estão seus lares?Como se constituem identidades?

Segundo Sarup, os estrangeiros parecem desempenhar dois papéis: podem ser positivos, reveladores da significação oculta da tribo ou negativos, intrusos que destroem o consenso. "Em certo sentido, o estrangeiro é um sintoma: do ponto de vista psicológico, significa a dificuldade que temos de viver como o outro ou com os outros" (1995, p. 276).

Encontrar o outro, o estrangeiro, possibilita o dar-se conta das próprias peculiaridades e limitações. O estrangeiro mostra o inadaptável, o incontrolável, o incongruente e o ambivalente. É uma "anomalia", mantendo-se entre o exterior e o interior. Para Sarup (1995, p. 278), precisa-se colocar 0 outro ser como "estrangeiro", porque este estigma é arma para a defesa contra o próprio estranhamento.

Os indivíduos contemporâneos atravessam uma larga cadeia de mundos sociais - habitam simultaneamente em vários mundos divergentes. $\mathrm{O}$ resultado é que estão desarraigados de todos os lugares e em nenhum se encontram em casa. A maioria de nós compartilha da experiência de ser estrangeiro. Assim, segundo Sarup (1995), em meio à carência de lar, os indivíduos se voltam as suas vidas privadas como único lugar em que podem esperar construir um lar.

A identidade é uma construção, é a conseqüência de um processo de interação entre pessoas, instituições e práticas. Dado que o âmbito da conduta humana é tão amplo, os grupos mantêm fronteiras que limitam o tipo de conduta em um território cultural definido. As fronteiras constituem um importante ponto de referência para quem quer participar de qualquer sistema. 
Sarup (1995) cita Kai Erikson (que por sua vez se baseia em Durkheim) afirmando que "a única maneira de sinalizar fronteiras é a conduta dos participantes". Um transgressor reflete a extrema variabilidade de conduta que pode registrar-se na experiência de um grupo. No interior das fronteiras a norma está vigente.

Segundo Durkheim, raramente uma regra social se expressa em uma regra firme; na realidade, é uma acumulação de decisões levadas a cabo por uma comunidade durante um largo período de tempo. A regra só mantém seu valor se utilizada com regularidade como fundamento do juízo. Cada vez que se castiga um ato de transgressão, agudiza-se a autoridade da norma e declara-se onde estão situadas as fronteiras do grupo. Deste modo é possível garantir-se a diversidade e a variabilidade que admite o sistema sem perder sua estrutura característica. Em resumo, transgressores e agentes de controle vão sendo mecanismo de manutenção dos limites. Segundo esta perspectiva é possível pensar-se o estrangeiro como transgressor que sinaliza os limites. Ele marca os limites exteriores à experiência de um grupo, constituindo-se em ponto de contraste.

As contribuições de Hall, Woodward e Sarup no que diz respeito à constituição da identidade têm implicações conceituais e existenciais que precisam ser devidamente consideradas. Por um lado somos impactados pelo hibridismo e pela diversidade. Por outro, há fortes tentativas de restaurar a coesão, o fechamento, numa tentativa de resgate da tradição. Há tendências à homogeneização, mas também perspectivas identitárias fragmentadas e multifacetadas. Os movimentos, em seus resultados, são contraditórios.

Creio que são possíveis múltiplas aproximações entre as considerações feitas acima e a vivência dos educadores religiosos. Temos vivido uma trajetória de identificações e "des-identificações". Talvez, estejamos sendo imigrantes cruzando fronteiras e haja uma distância entre nossas referências primordiais e o nosso momento presente. Será que, de certo modo, pensar o Ensino Religioso no espaço macro ecumênico não tem nos tornado criaturas híbridas, que precisam renascer, refazer-se como uma colcha de retalhos?

\section{Práticas discursivas e a constituição da identidade religiosa}

A importância da linguagem está em que o homem nela situou, ao lado do outro, um mundo dele só, um lugar que estimava bastante sólido para, apoiando-se nele, tirar o resto do mundo dos seus gonzos e tornar-se o seu senhor. Na medida mesma em que o homem acreditou nos conceitos e nos nomes das coisas como em outras tantas Aetema Veritates, ele fez verdadeiramente seu o orgulho com o qual se elevava acima do animal: imaginava realmente possuir na língua o conhecimento do mundo. $\mathrm{O}$ artista do verbo 
não era bastante modesto para ver que nada mais fazia do que atribuir denominações às coisas... é de fato ulteriormente, é quase só agora que os homens começam a se dar conta do enorme erro que propagaram com a sua crença na linguagem (NIETZSCHE, 1973, p. 11).

Os desafios da reflexão contemporânea estão lidando com uma situação irremediavelmente pluralista, que é, contraditoriamente, uma pluralidade na singularidade! O mercado hegemoniza tudo, a globalização é, ao mesmo tempo, plural (global) e singular (pela ação que unifica). Uma das questões relevantes é a desarticulação dos significados. Para que o significado denote alguma coisa presume-se a existência de algumas fronteiras estáveis, de estruturas fixas e de consenso partilhado (LYON, 1998, p. 112-113). A condição contemporânea é de fronteiras instáveis e em constante movimento. Conforme Foucault se engana, quem deseja descrever gêneses lineares - ao ordenar, (...) como se as palavras tivessem guardado seu sentido; os desejos, sua direção; as idéias, sua lógica; como se esse mundo das coisas ditas e desejadas não tivesse conhecido invasões, lutas, rapinas, disfarces, artimanhas ( ).

Silva (2000, p. 93) pontua considerações relevantes na caracterização da condição atual:

Incredulidade relativamente às metanarrativas, qualquer sistema teórico ou filosófico com pretensões de fornecer descrições ou explicações abrangentes e totalizantes do mundo ou da vida social; deslegitimação de fontes tradicionais e autorizadas de conhecimento, como a ciência, por exemplo; descrédito relativamente a significados universalizantes e transcendentais; crise de representação e predomínio dos 'simulacros' (os signos não mais remetem a referentes reais, mais a outros signos, onde não há possibilidade de representação fiel da realidade ou de formas ideais. Assim, simulacros são representações de representações; fragmentação e descentramento das identidades culturais e sociais" Entende-se como identidade cultural o conjunto de características que distinguem os diferentes grupos sociais entre si (SILVA, 2000, p. 94).

Percebe-se a consciência de uma "mudança de época", cujos contornos são imprecisos, confusos e ambíguos (WELLMER apud BERMAN, 1989, p. 319).

Há em comum, nas reflexões de diversos teóricos contemporâneos, o questionamento a todos os pensamentos do Ser e da representação. Concebendo a ausência de todo critério objetivo do verdadeiro, só existe a "vontade de verdade", que possibilita que se façam afirmações, sem ter de referi-las a uma norma transcendente, por definição, difícil de encontrar.

Uma síntese teórica possível de afirmação é que a evolução do pensamento se efetua de modo descontínuo. Em cada época há uma cultura 
própria que faz com que o pensamento seja prisioneiro dos limites que lhe são atribuídos pela estrutura determinada que subjaz a tal cultura, uma episteme que se constitui alicerce comum a todas as formas de saber. Para Delacampagne (1997, p. 251) é preciso uma ruptura subterrânea e radical na nossa maneira de encarar o mundo, para que haja transformação da episteme e assim seja possível pensar de outra forma.

Não é mais possível falar da verdade e do saber sem levar em conta as falhas e fraturas que as pesquisas de Foucault, por exemplo, provocaram no interior dessas categorias, nem é impossível ignorar que estas, longe de designar verdades transcendentais, têm uma história empírica.

Foucault é um pensador representativo de uma geração que perdeu a confiança nas grandes utopias sociais, não acreditando mais no sentido da história; utiliza-se de uma prática sistemática da suspeita para analisar os ideais em cujo nome o "progresso" histórico foi até então legitimado. Graças a ele, especialmente, e à corrente "pós-estruturalista", o debate sobre o fundamento da razão, seus poderes e seu futuro, tornou-se primordial.

Quais são as relações que temos com esses "jogos de verdade" que são tão importantes na civilização e nos quais somos, a cada vez, sujeito e objeto? Quais são as relações que entabulamos com os outros através dessas estranhas estratégias e relações de poder? Quais as relações entre verdade, poder e o si?

Partindo das considerações apontadas aqui e nos itens anteriores, existe uma gama de implicações que precisam ser analisadas. É preciso que se pense a relação entre as culturas religiosas e a constituição da identidade religiosa.

A subjetividade não se constitui fixa e definitiva, mas é plural e polifônica. Isso não significa uma pulverização generalizada do identitário, mas a possibilidade de um outro princípio de individuação, calcado em processos de singularização. A subjetividade não é una nem é múltipla, mas multiplicidades; não começa nem conclui, se encontra sempre no meio, entre coisas, interser, intermezzo (SARUP, 1995, p. 59). O processo de subjetivação é um movimento de devir, de vir a ser, como um complexo de distintas tendências ou forças que deve encontrar saída, produzir existências.

A cultura religiosa se constitui em uma fonte significativa de identidade cultural. A identidade religiosa é formada e transformada no interior da representação, ou seja, é um conjunto de significados que vieram a ser representados em nossa cultura religiosa, constituindo a possibilidade de uma determinada identidade religiosa.

A formação de uma cultura religiosa contribui para criar padrões de comportamento moral, ético, político, econômico, etc. As culturas religiosas são compostas de símbolos e representações. Uma cultura religiosa é um dis- 
curso - um modo de constituir sentidos que influenciam e organizam nossas ações quanto à concepção que temos de nós mesmos, do mundo, das relações, de nossas vidas e mortes, com os quais podemos nos identificar, construir identidades (HALL, 1999, p. 55-56).

O discurso sobre o religioso, seus enunciados, suas afirmações, são linhas de força em luta, vetores relevantes no processo de subjetivação dos indivíduos implicados na relação pedagógica. Embora no discurso no discurso do religioso possamos observar que, muitas vezes, a questão da identidade religiosa é tratada como se fosse possível haver identificações lineares, consistentes, localizadas e coerentes, consideramos que constituímos identidade religiosa a partir de uma série de discursos, de práticas, de tecnologias particulares pertencentes a tradições culturais identificáveis, não-coerentes e não unificadas, de tempos e lugares, e de táticas e estratégias. Somos reflexos de tecnologias humanas, seres múltiplos e híbridos, resultado de processos múltiplos de subjetivação. A noção de identidade como uma subjetividade racional, unificada e coerente foi uma invenção do projeto antropológico da Modernidade e esteve no centro do esforço da escolarização universal.

O discurso sobre o religioso na escola é parte integrante desses processos de subjetivação, próprios da escolarização e do exercício pedagógico, manifestam isso no modo como descrevem as formas singulares pelas quais se deve chegar a comportamentos desejáveis no governo de si e dos outros e na produção/fabricação de determinadas formas de subjetividade dos sujeitos pedagógicos, sejam eles alunos ou professores.

O discurso do religioso, ao tentar constituir um universo possível de significação, permite ao sujeito dar sentido a si mesmo e a tudo mais que o rodeia. A linguagem que engendra o discurso religioso/sobre o religioso fornece categorias de pensamento, conceitos e termos a partir dos quais é possível ao sujeito narrar e explicar-se a si mesmo, suas necessidades vitais e as suas relações.

Em outras palavras, a conduta, mesmo não sendo reflexo imediato do que é pensado ou dito, também se torna plausível pela intermediação da linguagem. Tendo isto em conta, é possível considerar a importância que tem o discurso religioso/sobre o religioso no espaço pedagógico, para além da produção e veiculação de certas formas de representação do mundo e do fenômeno educativo.

A pedagogia exerce uma forma de governo que produz e reproduz, em determinados momentos, regras e práticas particulares. Tais práticas são chamadas por Foucault de Tecnologias do Eu. Essas tecnologias podem ser entendidas como manifestações do eu interior, como a forma como as pessoas identificam a si mesmas ou ainda como expressões que remetem a um conjunto de práticas de automodelamento ou de "artes da existência". São exercícios 
e meios pelos quais os pensamentos, seus corpos e suas almas, seus desejos e afetos, seus modos de ser, de pensar e agir, a fim de transformar-se e alcançar certos tipos de comportamentos. O processo pedagógico corporifica relações de poder entre professores e aprendizes com respeito a questões de saber: qual saber é válido, qual saber é produzido, o saber de quem? É comum que se exerça a crítica com relação a discursos pedagógicos entendidos como "tradicionais", como se os mecanismos de poder-saber funcionassem apenas em relação a determinados discursos educacionais.

Os discursos críticos e emancipatórios não estão isentos dessa análise. Nesta perspectiva, não se concebe um mundo do discurso dividido entre o discurso admitido e o discurso excluído, ou entre o discurso dominante e o dominado; mas, ao contrário, como uma multiplicidade de elementos discursivos num jogo complexo e instável em que o discurso pode ser, ao mesmo tempo, instrumento e efeito do poder e também obstáculo, ponto de resistência e ponto de partida de uma estratégia oposta. O discurso veicula e produz poder; reforça-o, mas também o mina, expõe, debilita e permite barrá-lo. Não existe um discurso do poder de um lado e, em face dele, um outro, contraposto.

Considerar tais perspectivas implica considerar a participação do discurso sobre o religioso nos processos de subjetivação dos indivíduos; é considerar o seu papel e os seus efeitos de governo e de conduta na constituição de certas formas de experiência que os indivíduos possam ter de si mesmos, dos outros e do mundo, sejam eles aprendizes, docentes em exercício ou em processo de formação e treinamento.

Os discursos são instâncias de controle do que é e do que pode ser dito sobre alguma coisa, seus efeitos não são meramente simbólicos. Os discursos são práticas, são tecnologias, técnicas que têm efeitos produtivos sobre os sujeitos a que se dirigem e os objetos de que tratam. Tem-se concedido um status profissional, científico e intelectual para aqueles que estão encarregados de dizer o que conta como verdade.

Observar os mecanismos de nossas instituições educacionais, perguntar sobre a verdade de nossos próprios e cultivados discursos, examinar aquilo que faz com que sejamos o que somos, tudo isso abre possibilidades de mudança.

É importante considerarmos que os regimes de verdade não são necessariamente negativos, mas, antes, necessários. O saber e o poder estão freqüentemente ligados de forma produtiva. Transitamos por eles todo o tempo. É nossa condição de possibilidade. Pensar sobre os regimes de verdade que perpassam nossas práticas e funcionam como tecnologias do eu nos estimula a sermos mais humildes e reflexivos em nossas justificativas pedagógicas, teológicas, políticas, reconhecendo a necessidade de um trabalho des- 
construtivo que dê maior visibilidade a asserções de verdade e asserções de inocência que perpassam nossos discursos e práticas. A análise, a elaboração e o questionamento das relações de poder, dos regimes de verdades e das tecnologias do eu, presentes em nossos discursos, é uma tarefa permanente, pois o discurso é o caminho de uma contradição à outra. Segundo Foucault (1987), fazer com que desapareçam e reapareçam as contradições é mostrar o jogo que nele elas desempenham é manifestar como ele pode exprimi-las, dar-lhes corpo, exercer poder sobre nossas vidas e práticas.

À guisa de conclusão, cito palavras de Rubem Alves (1987), em seu texto Sobre Deuses e caquis:

Deus está muito além de nossas tramas verbais (...) Teologia não é rede que se teça para apanhar Deus em suas malhas, porque Deus não é peixe, mas Vento que não se pode segurar." (...) Descansem os que têm certezas. Não entro no seu mundo e nem desejo entrar. Jardins de concreto me causam medo. Prefiro a sombra dos bosques e o fundo dos mares, lugares onde se sonha... Ali moram os mistérios e o meu corpo fica fascinado.

Considerando suas palavras, concebo o exercício de reflexão sobre o Ensino Religioso como sendo o exercício de tecer redes, teias de significação e abro mão das certezas, porque desejo o fascínio de constituir novas possibilidades.

\section{Referências}

ALVES, Rubem. Da esperança. Campinas: Papirus, 1987.

ASSMANN, Hugo. Reencantar a educação: rumo à sociedade aprendente. Petrópolis: Vozes, 1998.

ALTHUSSER, Louis. Aparelhos ideológicos de Estado. 2. ed. Rio de Janeiro, RJ: Graal, 1985.

. For Marx. Londres: Verso, 1966.

BALEN, Age Deodorus Jozef van. Disciplina e controle na sociedade: análise do discurso e da prática cotidiana. São Paulo, SP: Cortez, 1983.

BAKHTIN, Mikhail. Marxismo e filosofia da linguagem. 3. ed. São Paulo, SP: Hucitec, 1986.

BAUDRLLARD, Jean. Simulacros e simulações. Lisboa: Relógio d’Água, 1991. 
BHABHA, Homi K. O local da cultura. Belo Horizonte: UFMG. 1998.

BOURDIEU, Pierre. O campo científico. In: ORTIZ. Renato (Org.). Sociologia. São Paulo, SP: Ática, 1994.

BRANDÃO, H. H. N. Introdução à análise do discurso. São Paulo, SP: Unicamp. 1992.

BRYSON, N.; HOLLY, M. A.; MOXEY, K. (Org.). Visual culture: images and interpretations. Hanover: Wesleyan University, 1994.

CONFERÊNCIA LATINO-AMERICANA E CARIBENHA DE CIÊNCIAS SOCIAIS, Relações Inter-étnicas e Globalização. 1, 1999, Recife. Anais ... Recife: Fundação Joaquim Nabuco, 1999.

CALHOUN, C. Social theory and the politics of identity. In: CALHOUN, C. (ed.). Social theory and the politics of identity. Oxford: Blackwell, 1994.

CANAVACCI, M. Dialética do indivíduo: o indivíduo na natureza, história e cultura. São Paulo, SP: Brasiliense, 1981.

CASTELLS, Manuel. The power of identity: the Information age: economy, society and culture. Oxford: Blackwell, 1997. v. 2.

CARON, Lourdes. Entreconquistase concessões: uma experiência ecumênica com enfoque na formação de professores. São Leopoldo: IEPG. 1995.

CASTIÑEIRA, Angel. Aexperiênciade Deus na pós-modernidade. Petrópolis: Vozes, 1997.

CERTEAU, M. de. A invenção do cotidiano. Petrópolis: Vozes, 1994.

CONFERÊNCIA NACIONALDOSBISPOSDO BRASIL Texto referencial para o ensino religioso: Regional Sul III. Petrópolis: Vozes, 1996.

CONNOR, Steven. Cultura pós-moderna: introdução às teorias do contemporâneo. São Paulo, SP: Loyola, 1992.

CORAZZA, Sandra Mara. História da infância sem fim. Ijuí: UNIJUÍ. 2000. CRESPI, Franco. A experiência religiosa na pós-modernidade. São Paulo, SP: EDUSC. 1999.

CONSELHO DO ENSINO RELIGIOSO DO ESTADO DO RIO GRANDEDO SUL Ensino Religioso: plano de estudos. Porto Alegre, 2003.

CORBISIER, Roland. Enciclopédia filosófica. Rio de Janeiro, RJ: Civilização Brasileira, 1987. 
DELACAMPAGNE, Christian. História da filosofia no século XX. Rio de Janeiro, RJ: Jorge Zahar, 1997.

DEWS, P. Adomo: pós-estruturalismo e a crítica da identidade. In: ZIZEK, S. A. Um mapa da ideologia. Rio de Janeiro, RJ: Contraponto, 1996.

DUCROT, Oswaldo. 0 dizer e o dito. Campinas: Pontes, 1987.

EIZIRIK, M. F.; COMERLATO, D. A escola (in)visível: jogos de poder/saber/ verdade. Porto Alegre: Editora da UFRGS. 1995.

EWALD, François. Anatomia e corpos políticos. In: FOUCAULT, M. As normas e o direito. Lisboa: Veja, 1993.

. Foucault, um pensamento inconfesso. In: Os deuses na cozinha. Lisboa: Arcádia, 1980.

FERRAZ, Maria Cristina Franco. Nove variações sobre temas nietzschianos. Rio de Janeiro, RJ: Relume Dumará, 2002.

FERREIRA, Amauri Carlos. Ensino religioso nas fronteiras daética. Petrópolis: Vozes, 2001.

FERREIRA, M. Cristina Leandro (Org.). Glossário de termos do discurso. Porto Alegre: UFRGS. 2001.

FERREIRA, Nilza Donizetti Dias. Da legislação à sala de aula: o percurso do ensino religioso na escola pública da cidade de São Paulo. São Paulo, SP: UMESP. 1999.

FACULDADE DE FILOSOFIA E CIENCIAS DA UNESP. Análise do discurso, Marília, v. 6, n. 2, 1997.

FIGUEIREDO, Anísia de Paulo. Ensino religioso: perspectivas pedagógicas. Petrópolis: Vozes, 1994.

FIGUEIREDO, L C. Modos de subjetivação no Brasil e outros escritos. São Paulo, SP: Escuta, 1995.

FIORIN, José Luiz. Linguagem e ideologia. São Paulo, SP: Ática, 2002.

FISKE, John. Power plays, power works. Londres: Verso, 1993.

FÓRUM NACIONAL PERMANENTE DO ENSINO RELIGIOSO. Parâmetros curriculares nacionais: ensino religioso. 2. ed. São Paulo, SP: AM. 1997.

- Capacitação docente: licenciamento - latu sensu - extensão para 0 ensino religioso. Brasília, DF: Universidade Católica de Brasília, 1998. 
FOUCAULT, M. A arqueologia do saber. 4. ed. Rio de Janeiro, RJ: Forense Universitária, 1995.

. A ordem do discurso. 5. ed. São Paulo, SP: Loyola, 1999.

Vega, 1992.

A vida dos homens infames. In:

. O que é um autor? Lisboa:

. Arqueologia das ciências e histórias dos sistemas de pensamento. Rio de Janeiro, RJ: Universitárias, 2000.

. As palavras e as coisas: uma arqueologia das Ciências Humanas. São Paulo, SP: Martins, 1990.

. El orden del discurso. México: Tusquets, 1987c.

; EWALD, François; DÉFERT, Daniel (Org.). Dits et écrits. Paris: Gallimard, 1994. v. 4.

. La arqueologia del saber. México: Siglo Veintiuno, 1987a. Graal, 1986.

; MACHADO, Roberto (Org.). Microfísica do poder. Rio de Janeiro, RJ:

. Vigiar e punir: história da violência nas prisões. Petrópolis: Vozes, 1987.

FRIDMAN, Luis Carlos. Vertigens pós-modernas: configurações institucionais contemporâneas. Rio de Janeiro, RJ: Relume Dumará, 2000.

GADET, F.; HAK, H. Por umaanálise automática do discurso: uma introdução à obra de Michel Pêcheux. Campinas: Pontes, 1990.

GERGEN, Kenneth J. El yo saturado: dilemas de la identidad en el mundo contemporáneo. Barcelona: Paidós, 1992.

Realities and relationships: soundings in social construction. Massachusetts: Harvard University Press, 1985.

GUIMARÃES, André Eduardo. O sagrado e a História: fenômeno religioso e valorização da histónia à luz do anti-historicismo de Mircea Eliade. Porto Alegre: EDIPUCRS. 2000.

GONTIJO, E.D. A abordagem estrutural e a questão do sujeito do ponto de vista da ética. In: MARI, H.; DOMINGUES, L; PINTO, J. (Org.). Estruturalismo: memórias e repercussões. Rio de Janeiro, RJ: Diadorim, 1995.

GRAÇA, Maria Manuela Alves. Pedagogias críticas e subjetivação: uma perspectiva foucaultiana. Petrópolis: Vozes, 2002. 
GREGOLIN, M. R. V. Recitações e mitos: a história na lente da mídia. In:

(Org.). Filigranas do discurso: as vozes da história. Araraquara: Cultura Acadêmica, 2000.

GNERRE, Maurizio. Linguagem, escrita e poder. São Paulo, SP: Martins Fontes, 1998.

GRUEN, Wolfgang. O Ensino religioso na escola. Petrópolis: Vozes, 1994.

HAL, Stuart. A questão da identidade cultural na pós-modernidade. Rio de Janeiro, RJ: DP\&A, 1999.

- A centralidade da cultura: notas sobre as revoluções culturais de nosso tempo. Educação \& Realidade, Porto Alegre: v. 22, n. 2, p. 15-46, jul./ dez. 1997.

. A questão da identidade cultural. In: HELD, D.; McGREW, T. (Org.). Modernity and its futures. Cambridge: Polity/Open University, 1992.

HUYSSEN, A. Mapeando o pós-modemo. In: HOLANDA, H. B. de (Org.). Pósmodernismo e política. Rio de Janeiro, RJ: Rocco, 1992.

JACOB, Cezar Romero etal. Atlas da filiação religiosa e indicadores sociais no Brasil. Rio de Janeiro, RJ: Loyola, 2003.

JAMENSON, Fredric. Pós-modernismo: a lógica cultural do capitalismo tardio. São Paulo, SP: Ática, 1996.

JUNQUEIRA, Sérgio R. Azevedo; MENEGHETTI, Rosa Gitana Krob; WASCHOWICZ, Lílian Anna. Ensino religioso esua relação pedagógica. Petrópolis: Vozes, 2002.

LACAN, J. The mirror stage as formative of the function of the I. In: Écrits: a selection. London: Travistock, 1977.

LACLAU, E. New reflections on the resolution of our time. Londres: Verso, 1990.

LÉVY, Pieme. Ciberespaço: um hipertexto com Pieme Lévy. Porto Alegre: Artes e Ofícios, 2000.

LYON, David. Pós-modernidade. São Paulo, SP: Paulus, 1998.

LYOTARD, Jean-François. O pós-moderno. Rio de Janeiro, RJ: José Olympio, 1993.

MACHADO, Roberto. Por uma genealogia do poder. In: FOUCAULT, M. Microfísica do poder. Rio de Janeiro, RJ: Graal, 1979. 
. Foucault, a filosofia e a literatura. Rio de Janeiro, RJ: Jorge Zahar, 2001.

MAIA, Antônio C. Sobre a analítica do poder de Foucault; tempo social. Revista de Sociologia, São Paulo, v. 7, n. 2, p. 83-103, out. 1995.

MAINGUENEAU, D. Novas tendências em análise do discurso. Campinas: Pontes, 1994.

. Termos-chave da análise do discurso. Belo Horizonte: UFMG. 1998.

MARX, K.; Engels, F. The communist manifest: Revolutions of 1848. Harmondsworth: Penguin, 1973.

MEKSENAS, Paulo. Sociedade, filosofiae educação. São Paulo, SP: Loyola, 1994.

MERCER, K. Welcome to the jungle. In:J. RUTHERFORD (Org.). Identity. London: Lawrence and Wishart, 1990.

MORA, José Ferrater. Dicionário defilosofia. São Paulo, SP: Martins Fontes, 1998.

MOURA, A. A política do sujeito: anuánio do laboratónio de subjetividade e política. Rio de Janeiro, v. 1, dez./dez. 1991/92. 1992,

NIETZSCHE, Friedrich. Aforisma 638, intitulado o viajan-te, In: Humano, Demasiado Humano, 1973.

ORLANDI, Eni Puccinelli. Discurso e leitura. São Paulo, SP: Cortez, 1993.

. Efeitos do verbal sobre o não-verbal. Revista do Núcleo de Desenvolvimento da Criatividade da Unicamp, Campinas, v.1, n. 1, p. 32-44, mar. 1995.

ORTEGA, F. Amizade e estética da existência em Foucault. Rio de Janeiro, RJ: Graal, 1999.

POLOCK, Griselda. Feminism/Foucault: surveillance/sexuality. In: BRYSON, N.; HOLLY, M. A.; MOXEY, K. (Org.). Visual culture: images and interpretations. Hanover: Wesleyan University, 1994.

POSSENTI, S. Discurso, estilo e subjetividade. Campinas: Pontes, 1990.

. Sobre as noções de sentido e de efeito de sentido. In: PÊCHEUX, M. Discurso: estrutura ou acontecimento. Campinas: Pontes, 1999.

RABINOW, Paul. The Foucault reader. New York: Penguin, 1991.

RUSS, Jacqueline. Dicionário de filosofia. Paris: Scipione, 1991.

SANTOS, B. De S. A. pela mão de Alice: o social e o político na pós-modemidade. Porto: Afrontamento, 1994. 
SARUP, Madan. Hogar, identidad y educación: volver a pensar la educación. Madri: Morata, 1995. v. 1.

SAUSSURE, Ferdinand de. Cours de linguistique générale. Paris: Payot, 1979.

SERRES, M. Filosofia mestiça. Rio de Janeiro, RJ: Nova Fronteira, 1993.

SILVA, Tomaz Tadeu da. Teoriacultural eeducação: um vocabulário crítico. Belo Horizonte: Autêntica, 2000.

. Identidade e diferença: a perspectiva dos estudos culturais. Stuart Hall, Kathryn Woodward. Petrópolis: Vozes, 2000.

SMTTH, Wilfred Cantwell. The meaning and end of religion. New York: Macmillan, 1962.

SPINK, Mary Jane. (Org.). P ráticas discursivas e produção de sentidos no cotidiano: aproximações teóricas e metodológicas. São Paulo, SP: Cortez, 1999.

TERRIN, Aldo Natale. Introdução ao estudo comparado das religiões. São Paulo, SP: Paulinas, 2003.

TEIXEIRA, Faustino (Org.). O diálogo inter-religioso como afirmação da vida. São Paulo, SP: Paulinas, 1997.

THERBORN, G. As novas questões da subjetividade . In: ZIZEK, S.A (Org). Um mapa da ideologia. Rio de Janeiro, RJ: Contraponto, 1996.

TOURAINE, Alain. Crítica da modernidade. Petrópolis: Vozes, 1994.

VATTIMO, G. El fin de la modernidad: nihilismo y hermenéu-tica en la cultura posmodema. Barcelona: Gedisa, 1998.

WELLMER, Albrecht. La dialectica de modemidad y posmoder, nidad. In: BERMAN, M. et al. El debate modernidad-posmodernidad. Buenos Aires: Untosur, 1989.

WITTGENSTEIN, Ludwig. Tractatuslogico-philosophicus. In:CHAUVIRÉ, Christiane. Wittgenstein. Rio de Janeiro, RJ: Zahar, 1989.

ZILLES, Unbano. Filosofia da religião. São Paulo, SP: Paulinas, 1991. 